\title{
Belphégor
}

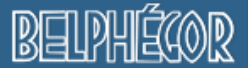

Littérature populaire et culture médiatique

18-2 | 2020

Roman Populaire Espagnol - Roman historique,

1900-1950

\section{Eduardo Zamacois: viajero, empresario, editor, periodista y escritor}

\section{Barbara Minesso}

\section{(2) OpenEdition \\ Journals}

Edición electrónica

URL: http://journals.openedition.org/belphegor/3042

DOI: $10.4000 /$ belphegor.3042

ISSN: 1499-7185

Editor

LPCM

Referencia electrónica

Barbara Minesso, «Eduardo Zamacois: viajero, empresario, editor, periodista y escritor », Belphégor [En ligne], 18-2 | 2020, mis en ligne le 11 décembre 2020, consulté le 28 avril 2021. URL : http://

journals.openedition.org/belphegor/3042 ; DOI : https://doi.org/10.4000/belphegor.3042

Este documento fue generado automáticamente el 28 abril 2021.

\section{(c)}

Belphégor est mis à disposition selon les termes de la Licence Creative Commons Attribution - Pas d'Utilisation Commerciale - Pas de Modification 4.0 International. 


\title{
Eduardo Zamacois: viajero, empresario, editor, periodista y escritor
}

\author{
Barbara Minesso
}

\section{Introducción}

1 Eduardo Zamacois no solo fue uno de los escritores más prolíficos y leídos en España durante la llamada Edad de la plata, sino que también supo, como pocos, interpretar y representar la temperie cultural de la época, contribuyendo a plasmarla con su infatigable trabajo de divulgación. Nacido en 1873 en Pinar del Río (Cuba) fue testigo y protagonista de muchos de los acontecimientos más significativos del tiempo en que vivió, desde el desastre al regeneracionismo, pasando por "aquella curiosa amalgama de idealismo y picaresca que constituía la bohemia española" (Barreiro 2001:33), el boom editorial de la colecciones de revistas dedicadas a la novela corta en el primer tercio del siglo XX, la Guerra Civil y el desarrollo de los nuevos medios de comunicación como el cine, la radio, la televisión.

2 Tanto como empresario cultural que como autor supo conectar con los gustos del público, consciente de su papel de escritor popular, intérprete de la vida colectiva, compenetrado con la masa de sus lectores y admiradores. En la "historia de mis libros" que precede a la novela epistolar El seductor (1902), Zamacois afirma que "el novelista se halla obligado, en cierto modo, a responder a cuantas consultas le dirigen sus adeptos, porque dada la similitud de sus sentimientos, nadie en mejores condiciones que él para orientarles y aliviarles en sus dolores". La novela, inspirada en una vivencia ocurrida a un amigo y en una carta escrita por un lector, es un ejemplo de la constante osmosis entre vida y literatura por parte de un autor que casi siempre ha vivido de su pluma y que ha alimentado su copiosa producción con mucho material humano, de carne y hueso. Si, por un lado, fue la necesidad apremiante lo que le llevó en ocasiones a buscar el favor del público, por otro, considerar las predilecciones de los lectores forma parte 
de su concepción artística. Así, las palabras del protagonista de Horas locas (1922), alter ego del autor: "el verdadero arte del narrador [...] consiste en conceder atención mayor, no a lo que él prefiere, sino a lo que prefieren los demás".

\section{Esbozo biográfico}

3 La vida andariega de sus padres lo llevó a diferentes ciudades: Bruselas, Paris, Sevilla para instalarse a los quince años en Madrid, cuyos cafés, bailes, librerías y redacciones lo conquistaron por completo. Abandonada la Facultad de Filosofía y Letras, se inclinó hacia la ciencia, entusiasmado por la lectura de Darwin, Haeckel y Spencer, a los que dedicó sus primeros artículos publicados en el semanario anticlerical Los Dominicales del libre pensamiento. Los fervores que sostuvieron los estudios en la Facultad de Medicina se enfriaron al entrar en contacto con el ambiente de la clínica y Zamacois decidió consagrarse plenamente al periodismo y a la literatura. Un elemento constante de su vida y de su obra fue la presencia de la mujer: innumerables fueron en ambas las aventuras galantes, los amoríos, las peripecias donjuanescas, pero el verdadero amor de su juventud fue París, con su alegría y su alma hecha de "gotas de ajenjo y espumas de champaña". Los años vividos en la Ville-Lumière, años de bohemia, pobreza, amores y locuras, reviven en un libro autobiográfico Años de miseria y de risa (1916), intenso y vibrante de emociones. El autor recuerda el hambre y el frío, los trucos para escaparse de los acreedores, el camino diario a la casa de empeño, las muchas piruetas de la suerte que le permitieron, entre otras, disfrutar del calor de diferentes servidoras de la bohemia. Imposible que la miseria sofocara la risa en una ciudad frívola e impredecible, donde "todo en ella, hasta sus propios dolores, al rodar sobre el limpio asfalto de sus aceras, se hacen alegría”. (120)

4 En 1910 Zamacois cumple su primer viaje al Nuevo Continente: un largo y grato periplo de dos años y, de vuelta a Madrid, se convierte en corresponsal de guerra para La Tribuna, encargo que le permitirá volver a su amada París y constatar amargamente que había perdido la liviandad y el aroma que la habían convertido en "la alcoba de Europa". En 1916 se encuentra nuevamente en América para llevar a cabo una gira en los teatros con el propósito de contar como vivían y trabajaban los grandes artistas españoles. Sus "charlas familiares", amenas e intencionalmente poco eruditas, pretendían mostrar a las personalidades tratadas desde el punto de vista personal y anecdótico y se completaban con proyecciones cinematográficas mostrando el ilustre en acción.

\footnotetext{
Las conferencias estaban concebidas como un espectáculo global donde se mezclaba literatura, cine y teatro, y donde además primaba la intención pedagógica basada en el principio clásico del docere et delectare. De nuevo Zamacois crea un revolucionario producto donde se conjugan una serie de elementos que garantizan el éxito seguro: la fusión de la palabra y el cine (texto e imagen), la representación en los teatros, el precio económico de la entrada, la publicidad en los medios de comunicación y a través de llamativos carteles, y, sobre todo, la idea de acercar al autor-artista al gran público a partir de anécdotas (causeries). Con todo ello, Zamacois pretende enseñar el movimiento cultural más reciente de España recurriendo al elemento lúdico. (Cabello 2012:236)
}

5 Si no fue difícil para Zamacois encontrar quien financiara el proyecto - la editorial Renacimiento, que por aquellas fechas estaba interesada en operaciones publicitarias para difundir la imagen de los autores de su catálogo (Jiménez León)- algo más 
complicado fue convencer a sus contemporáneos ilustres para dejarse filmar. Fue el bondadoso Benito Pérez Galdós el primero en romper el hielo, seguido por Ramón y Cajal y finalmente todos los demás (Valle Inclán, Benavente, Azorín y Baroja, Blasco Ibáñez, entre muchos otros)

Con las dos cintas realizadas, Zamacois viajó varias veces por el continente americano y, en su periplo, se entrevistó con personalidades de relieve, trabó amistades, cosechó aplausos, ganó dinero y, cómo no, coleccionó un sinfín de aventuras galantes.

Durante la Guerra Civil -cuyo estallido sorprendió a Zamacois en Madrid, su residencia habitual a partir de los años veinte- vivió entre Valencia y Barcelona, visitó los frentes de lucha e hizo diferentes incursiones en la capital para recopilar material destinados a los reportajes de guerra y sobre todo a su novela El asedio de Madrid (1938), himno a la ciudad sitiada, heroica, ejemplar. A pesar de mantenerse a lo largo de su vida "ajeno totalmente por preferencias y conducta personal a los problemas políticos nacionales" (Granjel 1980:28), su toma de posición a favor de la Republica fue desde el principio muy activa. En enero del 1939 alcanzó la frontera francesa con la hija, el nieto y Matilde, la mujer que le había de acompañar hasta sus últimos días; en 1933 había muerto Cándida, su esposa desde 1895, la mujer nacida para comprender y perdonárselo todo. Otra pirueta de la suerte, unida a la habitual picardía del autor, le permitió recalar en Francia y de allí, gracias a la ayuda brindada por amigos viejos y nuevos, embarcarse rumbo a Cuba.

Los treinta y dos años de exilio lo vieron cambiar de residencia varias veces - Cuba, México, Nueva York, Buenos Aires, ciudad donde se estabilizó a partir de 1946 - y multiplicar los esfuerzos para aliviar su situación económica. Colaboró con muchos periódicos y revistas y demostró, una vez más, su capacidad de asimilación de los nuevos medios de comunicación convirtiéndose en el personaje puntero de la radio cubana, con un programa que tuvo un éxito continental y, luego en México, escribiendo novelas radiales. Fue actor de doblaje cinematográfico en Nueva York contratado por la Metro Goldwin Mayer y en la Argentina obtuvo un puesto oficial en el Ministerio de Salud Pública. La tranquilidad económica de los últimos años -a su sueldo de funcionario se añadió la pensión otorgada por Instituto Nacional del Libro Español gracias a la mediación de F.C. Sainz de Robles- no le quitó cierta amargura que lo llevó a aislarse progresivamente del nutrido grupo de amigos argentinos y españoles y a obsesionarse con la idea de la muerte. El largo silencio como autor se interrumpió en 1964 con la publicación de sus memorias Un hombre que se va $a^{1}$. Tras visitar fugazmente España en 1969, el último día de 1971 falleció en Buenos Aires a los 98 años.

\section{La actividad editorial}

Dotado de gran espíritu empresarial, Zamacois dio vida a numerosos proyectos editoriales a partir de 1894 cuando, con Carlos Chíes, fundó El Libre Examen, semanario radical que salía de la imprenta montada por el mismo Zamacois gracias al dinero prestado por la madre. A pesar del esfuerzo titánico de los fundadores para defender la tribuna a la que subían "para hablar hebdomadariamente con el público que aplaudía desde provincias" (Zamacois, De mi vida, 1903:156) fue fuente de constantes preocupaciones tanto económicas como legales debido al tono furibundo de los artículos. La experiencia terminó pronto, pero Zamacois no renunció a su doble vocación de escritor y dueño de imprenta, como Balzac, y puso en marcha otra vez su 
Marinoni numero dos para imprimir La Justicia, diario republicano cuyo propósito era informar -de manera muy poco escrupulosa -sobre los últimos días de la guerra de Cuba, proponiéndose como alternativa a la prensa oficial. La intervención policial puso fin a la experiencia.

En 1897 Zamacois forma parte del grupo fundador de la revista Germinal, un semanario de orientación socialista y republicana, cuyos redactores, de los que el más carismático e ilustre era Joaquín Dicenta, aclaran desde el primer número que la cuestión social es el fulcro de su interés y saludan, junto con el siglo naciente, la revolución del proletariado. Germinal ofrecía cada viernes al lector las firmas más representativas que participaron al "espíritu del "98" (Paniagua 1964:44), con predominio de artículos doctrinales, políticos, sociales y económicos, al lado de comentarios humorísticos y relajados sobre hechos de actualidad y semblanzas. Por lo que se refiere a la literatura, en sus páginas conviven autores extranjeros (Victor Hugo, Gautier, Leopardi, entre otros) y españoles, como Baroja, Valle Inclán, Maeztu, Menéndez Pelayo, Salmerón, Blasco Ibáñez, Dicenta - cuyo Juan José es celebrado por Zamacois en la semblanza dedicada al autor como "una de las mejores -quizá la mejor - obra del teatro español contemporáneo". En Germinal "predominan artículos, cuentos o poemas de un fuerte sentimentalismo que pintan vívidamente la situación de miseria y desesperación de las clases trabajadoras" y, quizás por la influencia de Tolstoi, "era frecuente la presentación del contraste entre el cristianismo primitivo y la sociedad cristiana del momento" (Pérez de la Dehesa 1970:39). Uno de los no numerosos espacios que la revista dedicó a la guerra de Cuba se debe precisamente a Zamacois con sus Episodios de guerra (n. XXI, 1897), el único texto de ficción del pinareño que en Germinal firma sobretodo artículos doctrinales y filosóficos. La primera etapa de Germinal "un intento fallido de colaboración entre republicanos y socialistas, que fracasa por la dinámica de intransigencia de unos y otros" (Robles Egea 1982:410), se concluye con el número 24 y el traslado de muchos de los redactores, Zamacois incluso, al prestigioso El País.

11 Zamacois fundó en 1898 con el que sería el editor de sus primeras novelas, Ramón Sopena, La Vida Galante una revista que se añadió al nutrido catálogo de productos editoriales que, vendidos en los quioscos, ofrecían cuentos galantes, frívolos, eróticos, sicalípticos. "La aparición de estas novelitas eróticas supuso en la novela corta una gama más amplia de ejercicios literarios, con la creación especial de un lenguaje, un grafismo y una ilustración que en la mayoría de casos aparecía bajo el seudónimo, el anonimato y hasta la clandestinidad"(Blas Vega 1993:37). Resulta patente la influencia de la literatura francesa en los cultores del género y la "«tiranía» dulce, sensual y jocunda" (López Ruiz 2001:11) de París, con su moda, música, bailes y divettes atraía al público español. Incluso en el aspecto editorial de las revistas eróticas españolas se imponía la moda francesa y La Vida Galante "se proponía recoger el aroma de alcoba que perfuma la literatura francesa del siglo XVIII; una publicación traviesa, con historietas de mujercitas locas y maridos de vodevil, aunque sin audacias de mal género" (Zamacois 2011:231). Zamacois, que fue director del semanario hasta 1902 y prácticamente único redactor de los primeros números, no dejó de firmar asiduamente cuentos, crónicas y semblanzas incluso cuando el éxito de la revista, convertida en una de las más importantes del género, le permitió contar con talentosos colaboradores como Dicenta, Benavente, Gómez Carrill y, Pedro Barrantes, entre otros.

El erotismo teorizado por Zamacois en las páginas de $L a$ Vida Galante se configura como un antídoto al malestar generacional y al tedium vitae debidos al desastre nacional: 
A las carnes putrefactas, renegridas o amarillentas de los soldados que volvían de Cuba [...] sustituye Zamacois la Carne deseable y gozosa de la vida. A la Madre Patria, devoradora y arcaica, genitrix y fálica [...] sustituye Zamacois el Placer sin más meta que el gozar plenamente de la vida, de su cuerpo, de la lozanía de las fuerzas físicas, la embriaguez que invita a crear otro mundo más fácil, más fútil pero donde es posible vivir. (Robin 1997:228)

13 El propósito de la revista parece claro desde el primer número: “mientras otros se afanan en luchas políticas y controversias religiosas, nosotros emprendemos la cruzada del amor, entonando un himno al placer y procurando infiltrar en los corazones desmayados y abatidos el regocijo de vivir" (n. I, 1898:2). Y esta joie de vivre pasa por supuesto por Paris con sus cocottes, bailarinas y actrices que las bellas ilustraciones de la revista retratan "ligeras de ropa o semidesnudas y en posturas insinuantes" (Ezama Gil 1988:79). Los cuentos firmados por Zamacois en La Vida Galante presentan por lo general un erotismo sin complicaciones, pero a veces pone en escena la lucha entre el espíritu y la carne, eligiendo come protagonistas a clérigos o eremitas (Fray Pedro, n. X, 1899). Otro protagonista de algunos de sus cuentos es Don Juan (Boda eterna, n.VIII, 1898; Don Juan. Fantasía carnavalesca, n.LIX, 1900), no ya joven y gallardo sino anciano y aislado, atormentado por los recuerdos, un Don Juan que "usa muletas", exactamente como se define en una ocasión el autor pinareño. Y hablando de las mujeres protagonistas, son por lo general frívolas y caprichosas pero capaces también de concebir grandes amores, grandes sacrificios, sobre todo para salvar a sus hijos (Disyuntiva cruel n. LX, 1899), y odios salvajes (Odio mortal, n. II, 1898), Agonía, n. XXIX, 1899).

La Vida Galante dejó de publicarse a finales de 1905 y, según Ezama Gil, "tal vez no fueron ajenas al cese las denuncias de que la revista es objeto en 1904, acusada de pornografía, o dificultades económicas, lo que, quizá, revierte en la baja calidad de la revista durante 1905" (74). En 1904 Zamacois se lanzó a otro proyecto editorial, junto a su amigo Joaquín Segura: se trataba de la Editorial Cosmópolis, fundada en Madrid gracias al apoyo económico de José Carrascal, con el propósito de traducir al francés las mejores novelas españolas contemporáneas. Para ello, Zamacois se trasladó a París en busca de buenos traductores y tipógrafos. Consiguió reclutar una "chusma indisciplinada" de colaboradores, que pasaron a vivir directamente en la sede de la editorial, lo que, junto a la impaciencia de los socios fundadores, determinó el fracaso de la experiencia. El catálogo de la editorial se reduce a cuatro títulos: dos obras en francés (El seductor, del mismo Zamacois y Doña Perfecta, de Pérez Galdós, que cedió gratuitamente los derechos) y dos en español, publicadas sin contar con la opinión de Zamacois: una obra del anticlerical Ramón Chíes y un manifiesto pro-republicano firmado por Barriobero. La sospecha es que, mucho más que Zamacois, "Carrascal y Segura querían utilizar la editorial como órgano de difusión propagandística de sus ideales políticos. Lo cual imprime una doble naturaleza-literaria y política- a la Casa Editorial Cosmópolis" (Cabello 2012: 232).

Una noche en la que el agobio por las estrecheces económicas le quitaba el sueño, Zamacois concibió la revista destinada a revolucionar al panorama editorial y literario español:

No hubo en mi concepción el menor titubeo. Desde el primer instante se dibujó en mi imaginación, clara, precisa. Con los ojos del alma la veía según nació después. Cada número, de veinticuatro páginas, de papel "couché", lo ocuparía una novela corta, inédita, ilustrada en colores y con la caricatura del autor en la portada. Nada más. Colaborarían en ella los escritores y dibujantes más reputados, y aparecería los 
viernes - precisamente los viernes - al precio de treinta centésimos ejemplar.

(Zamacois 2011:332)

Y así fue exactamente como El cuento semanal apareció en los quioscos el primer viernes del año 1907 con una novela corta de Jacinto Octavio Picón, después de "una gestación laboriosa y activísima de más de cuatro meses" (El Cuento Semanal, n. LII, 1907) y el dinero invertido por Antonio Galiardo. Zamacois publicó en el número cuatro su novela corta La cita y de "cita" habla Mainer para referirse a la revista - cuya fórmula resultó un éxito rotundo y fue imitada por centenares de colecciones parecidas - "una cita física que había convocado a unos lectores, había sometido a sus pautas a unos autores y también habían imaginado unos concretos empresarios" (Mainer 1986:208). Elementos que no es el momento de analizar como las características de El cuento semanal, las razones de su éxito, la importancia de las ilustraciones, la publicidad y los recursos para fidelizar el lector, la compenetración de éste en el universo retratado en la revista, las conexiones con el periodismo, la recuperación de la novela corta como género narrativo, la incorporación de nuevos autores a la literatura y la difusión del hábito de la lectura, entre otros, han merecido la atención de la crítica, a partir del estudio de Sainz de Robles. Harto conocidas son también las circunstancias - el suicidio de Galiardo, el pleito ganado por la viuda de éste - que llevaron Zamacois a separarse de su criatura para fundar en 1909 Los Contemporáneos, revista del todo similar al Cuento Semanal que durante años se disputó con su rival el favor del público lector. La incompatibilidad entre el pinareño y el que pasó a ser el único dueño de la revista determinó el cese de su cargo de director a un año de la fundación de Los Contemporáneos, lo que no impidió que Zamacois colaborase como autor llegando a publicar en ella once novelas cortas.

\section{La obra literaria}

17 En la copiosa producción en prosa de Zamacois, la autobiografía ocupa un lugar fundamental, bien sea como recuerdos de viajes, Dos años en América (1913), La alegría de andar (Croquis de un viaje por tierras de Puerto Rico y Cuba, Estados Unidos, Centro América y América de Sur, 1916-1920) (1920), De Córdoba a Alcazarquivir. Tipos y paisajes de Andalucía y Marruecos, 1915-1921, (1921), bien sea como memorias: De mi vida (1903), Mirando hacia atrás (Páginas autobiográficas de una vida en que sólo hubo erratas) (1915), Años de miseria y de risa (1916), Confesiones de un "niño decente". Autobiografía (1921) hasta llegar a 1964 cuando Un hombre que se va interrumpió el largo silencio del autor después del exilio. Es más: muchos de los protagonistas de su narrativa se ven empeñados en la tarea de hilvanar los recuerdos, mujeres (Memorias de una cortesana, 1903), hombres que se parecen mucho a su creador (Horas locas, 1922; Una vida extraordinaria, 1923), e inclusive objetos como en el caso de la lograda Memorias de un vagón de ferrocarril (1922), que Entrambasaguas incluyó entre las "mejores novelas contemporáneas".

Con su obra autobiográfica Zamacois no solo deja constancia de su existencia sino también de la de muchos artistas, escritores y periodistas, sus contemporáneos, lo cual convierte estas páginas en un imprescindible documento de época. Las memorias ofrecen importantes informaciones acerca de la poética del autor, las circunstancias que inspiraron sus libros, la fibra humana de estos y la valoración estética del creador acerca de su obra. Zamacois propone una división de su producción en tres etapas distintas desde el punto de vista cronológico y argumental: 
Mi producción, de la que sólo citaré aquí las obras en que puse mayor esfuerzo, ofrece tres momentos perfectamente definidos. El pasional, que agrupa siete novelas, se inicia con Punto negro (1897), sigue con El seductor (1902) y Memorias de una cortesana (1903) y termina en 1905 con Sobre el abismo. A este periodo sucede otro, que llamaré de "indecisión o transición”, en que el sentimiento amoroso me preocupa menos, y me aventuré por los pagos del misterio y la ironía. Comienza con El otro (1910), al que siguen cinco novelas, de muy diverso linaje: Europa se va... (1913), La opinión ajena (1913), El misterio de un hombre pequeñito (1914), Memorias de un vagón de ferrocarril (1922), y acaba con Una vida extraordinaria (1923). Vienen luego mis novelas de ambiente social: Las raíces (1927), Los vivos muertos (1929) y El delito de todos (1933), que son las tres primeras novelas de un ciclo de siete volúmenes que la guerra me impidió escribir. (2011: 116)

El ingrediente erótico, pasional y galante predomina pues en la primera producción literaria de Zamacois, que cultiva durante los mismos años una narrativa breve mucho más liviana con respecto a sus novelas en las que la adhesión a la corriente naturalista queda patente, al punto de que José Ignacio Ferreras atribuye al autor el papel de "verdadero fundador de la corriente erótica, dentro del naturalismo" (1988:56). "Las novelas y las revistas galantes auspician una imagen del eros vital y desinhibido, en franca divergencia con la visión pesimista que de él ofrecen los militantes del naturalismo" (Fernández 1995:75). Efectivamente las novelas de la primera época de Zamacois se caracterizan por la presencia de la enfermedad, la neurosis y la locura, elementos que permiten al autor emplear sus conocimientos médicos. La fenomenología del amor, un detallado análisis psicológico de los personajes, junto con cierta inclinación a la premonición a través de los sueños y el tarot son elementos imprescindibles de esta fase de su narrativa. Si "el amor sexual es la ley obligada de todos los temas tratados [...] alrededor de este tema había buenas recreaciones del universo madrileño que el autor conoce muy bien" (Ferreras 1988: 57). Y, en efecto, la casi totalidad de las novelas galantes de Zamacois se sitúan en la calles, teatros y cafés de Madrid poblados por artistas, pintores, actrices, nobles, clérigos y cortesanas que traspasan de una novela a otra creando un universo unitario a la manera de Balzac y de Galdós.

Convencido de que los grandes artistas trabajan retratándose en sus obras, poniendo en ellas "jirones de su alma", Zamacois se inspira en hechos autobiográficos para crear la base argumental de varias de sus primeras novelas. La protagonista de La enferma (1894) - reimpresión de Consuelo aparecida el mismo año - recuerda un amor de juventud exactamente como Matilde, protagonista de Punto Negro (1897). En esta novela, escrita cuando Zamacois empezaba la colaboración con Germinal, el primer encuentro entre Claudio, un pintor obsesionado por la fama y Matilde, una guapa malcasada que se convertirá pronto en su amante, ocurre en un tranvía que, desde la Puerta de Sol, transporta una humanidad mísera de obreros sudados y mal vestidos, agobiados por el cansancio hasta un barrio periférico de la capital, demostrando la gran maestría del autor en la pintura del paisaje urbano y humano, con un atractivo toque costumbrista. Si Claudio en un primer momento se siente condolido observando a los obreros, cuando ve que la mujer que ha llamado su atención corresponde a su mirada, se olvida de las penas de los demás. La felicidad de los preliminares de un amor enigmático le quitan las ganas de ser socialista, puesto que "el socialismo es el credo político de los que sufren". Estamos evidentemente lejos del universo de crítica social de Germinal y el lector se prepara a entrar en un mundo galante hecho de deseo y de exaltación carnal, no sin complicaciones. A pesar de los muchos y variados encuentros carnales de los 
protagonistas, el alarde de erudición, el lenguaje científico y las largas digresiones pictóricas y mitológicas obligan el lector "a dejar el mundo del deseo para introducirse en el ámbito de la comprensión y reflexión" (Goulemot 1996:155).

21 A raíz de esta época pasional, parte de la crítica reconoció en Zamacois, junto con Felipe Trigo, el iniciador y maestro de la corriente erótica española, pero precisamente por ello, otra parte de la crítica lo apartó de su interés y obvió su evolución literaria, tachando superficialmente su obra de obscena. Además, el editor de las primeras novelas, el antiguo amigo Ramón Sopena, contribuyó a obstaculizar el camino del pinareño hacia la merecida respetabilidad literaria, con ediciones baratas, vendidas en los quioscos con portadas que envilecían las novelas. Cuando la Editorial Renacimiento brindó a Zamacois la oportunidad de publicar sus obras completas, él aprovechó para rescatar algunas de ellas, dándoles nueva apariencia y llegando en ocasiones a reescribirlas.

El cambio en la narrativa de Zamacois, su mayor interés hacia el misterio, en detrimento de los lances pasionales coincide con la evolución del naturalismo español dispuesto a tratar temáticas cercanas a la espiritualidad, el misticismo, el más allá o la psicología, considerada ya una rama autónoma, desvinculada de la fisiología. Si Sobejano habla de "quiebra" del naturalismo, Pattison se refiere a un "pequeño cambio de acento para llegar al naturalismo espiritual" (1969:147) y López Sanz confirma que el naturalismo modo hispano ya se caracterizaba por "un anhelo de espiritualidad y de psicologización" (1985:122). La insatisfacción y la inquietud llevan al hombre de fin de siglo a superar el positivismo explorando nuevos espacios, realidades transcendentes y sondear estados mentales que ya no se consideran únicamente como resultantes de las condiciones físicas y del ambiente (Goulemot). Para Zamacois, el nuevo horizonte narrativo se manifiesta a partir de la publicación de El Otro (1910) - novela llevada a la pantalla en 1919 con la actuación del mismo Zamacois que, en la ocasión, se estrena como actor de cine (Quesada)- y se confirma con El misterio de un hombre pequeñito (1914). Pesadillas y desdoblamientos, sueños premonitorios y disociaciones psíquicas, proyecciones astrales $\mathrm{y}$, más genéricamente, el mundo de lo paranormal - elementos que de manera más soslayada habían aparecido ya en algunas de sus novelas anteriores y volverán a aparecer posteriormente - son los ingredientes más importantes de estas novelas en las que el autor no renuncia, por un lado, al erotismo, que aquí se tiñe de tintas hoscas y, por otro, a un armazón realista y racional. "Sus obras de misterio sobrenatural se desarrollan en un cuadro contemporáneo realista que aumenta la impresión de verosimilitud"; el resultado es una "mezcla poderosa de plausibilidad racionalista y sugestión terrorífica" (Soler 1981:185). Muy plausible y realista es también la recreación del ambiente provinciano de un pueblo castellano de principios de siglo XX, escenario de la novela irónica La opinión ajena (1913), de la que siempre el autor se sintió muy orgulloso. A pesar de la vulgaridad y la hipocresía de la sociedad representada, cuya curiosidad malsana y fiscalización resultarán fatales para el bondadoso protagonista, la mirada del narrador hacia la humanidad retratada no deja de ser tolerante y compasiva, cifrándose así las distancias con el Galdós de Doña Perfecta o el Clarín de La Regenta.

23 Con la tercera etapa de su producción, Zamacois vuelve al seno del naturalismo, eligiendo el Ambiente como protagonista para el que, en su proyecto, debía ser un ambicioso ciclo narrativo y que, debido al estallido de la guerra, se redujo a una trilogía. Con Las raíces (1927) se inicia la epopeya de los Santoyos, una historia de cainismo, 
mezquindad y violencia ambientada en Castilla, con elementos de crítica social y pujos regeneracionistas. Los vivos muertos (1929) cuenta las vivencias de uno de los Santoyos en la cárcel y para documentarse acerca de la vida de los presos, el autor obtuvo licencia para visitar y vivir en varios presidios, ocasión que no desaprovechó para promocionar su novela en la prensa. Por último El delito de todos (1933) describe la caída de la dulce y sumisa Águeda que, humillada y violada, huye hacia Madrid, aquí descrita en la miseria y crueldad de sus barrios bajos, para perderse irremediablemente.

\section{Conclusión}

Largo y variado fue el recorrido vital y artístico de Eduardo Zamacois, periodista, escritor, editor, empresario que conoció el éxito y supo reaccionar con inagotable fuerza de ánimo a las desdichas. Perteneciente a la "raza maldita de los que sólo adoran lo lejano, lo inasequible, lo que nadie obtuvo" (Zamacois, La cita, 1907) tradujo sus inquietudes en una irreductible afición a los viajes convirtiendo los barcos y los trenes en materia narrativa. Así describe los primeros en sus memorias, dejando entre líneas su propia semblanza:

Los barcos, los eternos romeros del mar, tienen alma de artista. [...] En los puertos se enmohecen, se anquilosan, se pudren. Nacieron para emigrar, para irse. Simbolizan la inquietud. Ningún lugar del globo parece convenirles; diríase que todos les aburren, que ninguno es el que buscaban, y luego de reposar en ellos un tempo reanudan su camino. (Zamacois 2011:598)

El tren, objeto de amor incondicionado, es omnipresente en su obra, protagonista absoluto de Memorias de un vagón de ferrocarril, su paso determina algunos de los momentos claves de la acción de El misterio de un hombre pequeñito y con su horario de salida, las once menos un minuto, inspira una honda reflexión a uno de los protagonistas de Las Raíces "Si los hombres supiesen todo lo que cabe en un minuto bien aprovechado - parecía explicarle la locomotora- la vida no se le figuraría tan breve".

Periodista enamorado de su profesión, Zamacois no pierde ocasión de tejer una alabanza al periódico, instrumento de evasión y distracción, "un viaje rapidísimo hecho alrededor del globo y sin moverse de su butaca, un eco del mundo; la voz de los humanos que diariamente se comunican sus impresiones por medio del telégrafo" (Zamacois, Punto Negro, 1897). El periódico es la única ventana abierta sobre el mundo, en un ambiente asfixiante como el de la cárcel de Los vivos muertos y, finalmente, un instrumento fundamental para la difusión de las noticias de guerra en $\mathrm{El}$ asedio de Madrid, novela en la que se aprecia la actitud del periodista en la precisión con la que refiere lugares, fechas, acontecimientos. En una carta desde Valencia, con fecha 7 de noviembre de 1937, Zamacois informaba a Matilde, que estaba trabajando febrilmente en la redacción de El asedio de Madrid, devorado por un "anhelo calenturiento" de superación y que pensaba apostillarla como el maestro Hugo hizo con Los Miserables: "Si no consigo llamar la atención del público con este libro, no volveré a escribir nunca". Y, en efecto, ésta fue su última novela, pero, afortunadamente, el autor no llegó a a abandonar completamente su pluma. 


\section{BIBLIOGRAFÍA}

Javier Barreiro, Cruces de bohemia, Zaragoza, UnaLuna, 2001.

José Blas Vega, “La novela corta erótica española”, El Bosque, n.10, 1995, pp.35-45

Ana Cabello, "Eduardo Zamacois: empresario cultural y viajante de la literatura", Revista de estudios hispanicos, 46, 2012, pp: 223-245.

Joaquín de Entrambasaguas, Las mejores novelas contemporáneas, Tomo VI (1920-1924), Barcelona, Planeta, 1971.

María Ángeles Ezama Gil, "La ilustración de los relatos breves en la revista la Vida Galante", Boletín de Museo e Instituto Camón Aznar, 34, 1988, pp.73-96.

Pura Fernández, “Censura y práctica de la transgresión: los dominios del eros y la moralidad en la literatura española decimonónica”, en José Antonio Cerezo, Daniel Eisenberg, Víctor Fuentes (ed.), Los territorios literarios de la historia del placer. I Coloquio de Erótica Hispana (Montilla, Casa del Inca, 18-30 junio 1993), Madrid, Huerga\&Fierro, 1995, pp.71-88.

Juan Ignacio Ferreras, La novela en el siglo XX (hasta 1939), Madrid, Taurus, 1988.

Jean Marie Goulemot, Esos libros que se leen sólo con una mano: lectura y lectores de libros pornográficos en el siglo, Alegia (Guipúzcoa), Oria, 1996.

Luis Granjel, Eduardo Zamacois y la novela corta, Universidad de Salamanca, 1980.

Marcelino Jiménez León, "La primera aventura cinematográfica de Eduardo Zamacois” en Actas del XII Congreso de la asociación de Hispanistas, Madrid, 6-11 luglio 1998, Carlos Alvar Ezquerra, Florencio Sevilla Arroyo, (coord.), Madrid, Castalia, v.4, 2000, pp.373-382.

Mariano López Sanz, Naturalismo y espiritualismo en la novelística de Galdós y Pardo Bazán, Madrid, Pliegos, 1985.

José María López Ruiz, Los pecados de la carne. Crónica de las publicaciones eróticas españolas, Madrid, Temas de Hoy, 2001.

Mariano López Sanz, Naturalismo y espiritualismo en la novelística de Galdós y Pardo Bazán, Madrid, Pliegos, 1985.

José Carlos Mainer, “‘El Cuento Semanal〉 (1907-1912) Texto y contexto”, en Yves-René Fonquerne e Aurora Egido (coord), Formas breves del relato: coloquio de Casa Velázquez, Zaragoza, Universidad de Zaragoza- Madrid, Casa Velázquez, 1986, pp.207-220.

Domingo Paniagua, Revistas culturales contemporáneas, v.I. De Germinal a Prometeo, Madrid, Punta Europa, 1964.

Walter Pattison, El naturalismo español. Historia externa de un movimiento literario, Madrid, Gredos, 1969.

Rafael Pérez de la Dehesa, El grupo Germinal, una clave del 98, Madrid, Taurus, 1970.

Janice Soler, "El espiritualismo en las novelas de Eduardo Zamacois", Revista de Estudios Hispánicos, 1981, pp.181-197.

Luis Quesada, La novela española y el cine, Madrid, Ediciones JC, 1986. 
Claire-Nicolle Robin, “Eduardo Zamacois o la fiesta del cuerpo", en Antonio Cruz Casado, El cortejo de Afrodita: ensayos sobre literatura hispánica y erotismo, Málaga, Universidad de Málaga, 1997, pp. 221-232.

Antonio Robles Egea, "Republicanismo y socialismo reformista en la crisis del 98: las ideas del grupo «Germinal»", Estudios de historia social, n.22-23, 1982, pp.379-409.

Federico Carlos Sainz de Robles, La promoción de “El Cuento Semanal”, Madrid, Aguilar, 1952.

Gonzalo Sobejano, "La quiebra del naturalismo española del final de siglo", en Leonardo Romero Tobar (ed.) El camino hacia el 98 (los escritores de la Restauración y la crisis de fin de siglo), Madrid, Visor: Fundación Duques de Soria, 1998, pp.16-28.

\section{NOTAS}

1. En 1963 Rodolfo Schelotto, amigo y albacea de Zamacois, viajó a Barcelona para entregar el manuscrito a la editorial AHR (Alfonso Herrero Romero). Al año siguiente salía Un hombre que se va. Memorias. La segunda edición de 1969, revisada por el autor, se debe a la bonaerense Rueda y la última, reproducción de la segunda, se debe a la Editorial Renacimiento de Sevilla en 2011 con edición a cargo de Javier Barreiro y Bárbara Minesso. En este artículo se hace referencia a esta última edición. Rodolfo Schelotto es depositario del legado del autor pinareño, un valioso caudal de cuartillas inéditas, cartas y documentos, parte del cual he podido consultar después de ser adquirido en 2007 por la Biblioteca Nacional de España. Este fondo se encuentra hoy en el Archivo Histórico Nacional y ha sido en parte digitalizado (consultable en www.pares.mcu.es)

\section{RESÚMENES}

Este artículo propone un acercamiento a la actividad editorial y la obra literaria de Eduardo Zamacois (Pinar del Río 1873- Buenos Aires 1971) que, con inagotable fuerza de ánimo y gran espíritu empresarial, dio vida a proyectos que favorecieron la difusión y el éxito de la narrativa popular en España en las primeras tres décadas del siglo XX. Servidor de la bohemia de entre siglos, enamorado de París donde vivió años de miseria y de risas, formó parte del grupo fundador de Germinal, ideó el semanario sicalíptico La Vida Galante y fue protagonista del boom editorial de las colecciones de novela corta publicadas en formato de revista, a partir de El cuento semanal (1907) y Los Contemporáneos (1909).

Por lo que se refiere a la copiosa producción narrativa de Zamacois, el mismo autor distingue tres etapas distintas y cronológicamente consecutivas: a una primera época "pasional" sigue una fase de "transición e indecisión" en la que el misterio y la ironía le ganan terreno al erotismo para virar con la tercera etapa hacia novelas de ambiente social.

\section{ÍNDICE}

Mots-clés: Zamacois, collections populaires, fin-de-siècle, littérature populaire, presse 
AUTOR

BARBARA MINESSO

Università degli studi di Milano/SSML Carolina Albasio Castellanza

barbara.minesso@gmail.com 